\title{
Outcomes Of Adolescent Pregnancy at Kathmandu University Hospital, Dhulikhel, Kavre
}

\author{
Pun KD, ${ }^{1}$ Chauhan $\mathrm{M}^{2}$
}

\author{
${ }^{1}$ Nursing Program, ${ }^{2}$ B Sc in Nursing \\ Kathmandu University School of Medical Sciences, \\ Dhulikhel Hospital, Kavrepalanchowk, Nepal.
}

\section{Corresponding author:}

Kunta Devi Pun

Kathmandu University School of Medical Sciences,

Dhulikhel Hospital, Kavrepalanchowk, Nepal

email: knt_pun@yahoo.com

\section{Citation}

Pun KD, Chauhan M. Outcomes of Adolescent Pregnancy at Kathmandu University Hospital, Dhulikhel Hospital. Kathmandu Univ Med J 2011;33(1)50-3.

\begin{abstract}
Background

Adolescence Pregnancy is a social problem worldwide with serious implication of maternal and child health. This study purposed to compare the maternal and neonatal outcome of the teenage mothers (15- 19 years) with that of the young mothers (20-24 years) to determine if adolescent pregnancies have increased risk of adverse outcomes.
\end{abstract}

\section{Objectives}

This st udy aims to find out the outcomes of adolescent pregnancy at Kathmandu Univeristy Hospital, Dhulikhel Hospital, KAvre.

\section{Methods}

Descriptive cross sectional study was done. The study included all primiparous mothers of age 15-19 $(n=168)$ and 20-24 $(n=401)$ recorded in the delivery record book of Dhulikhel Hospital from June 2007 to May 2008. Chi-square test and relative risk (RR) for subgroups of study population was examined using the SPSS version 10.0.

\section{Results}

The low birth weight baby among teenage mothers and young mothers were $28 \%$ and $26.7 \%$ respectively $(p=0.572)$. The Relative risk of low birth weight among adolescent is $1.1(0.75-1.684)$ times to that of young mothers at $95 \%$ confidence interval. Preterm birth was not associated with adolescence pregnancy ( $7 \%$ Vs. $11.5 \%$, $\mathrm{p}=0.141$ ). Normal delivery was the common mode of delivery among both groups (77.4\% Vs. 74.6\%). Among the neonatal complication, newborns of adolescents had greater neonatal complications than newborns of the young mothers $(17.2 \%$ Vs $16.7 \%)$. Maternal complication like antepartum hemorrhage (2.4\% Vs. $1.7 \%)$ and postpartum hemorrhage $(0.6 \% \mathrm{Vs} .0 .2 \%)$ was higher among adolescents.

\section{Conclusions}

Low birth weight, common neonatal complication, antepartum hemorrhage and postpartum hemorrhage are found more in adolescent group, however statistically insignificant.

\section{KEY WORDS}

Adolescent, Outcome of pregnancy, primiparous, teenage mothers, Young mothers

\section{INTRODUCTION}

The term "adolescents" refers to individuals between the ages of 10-19 years. ${ }^{1}$ They make up more than one billion, i.e, nearly one-fifth of the world population, are growing in number, and virtually, this growth is in developing countries. $^{2}$ The rapid population growth rate is also a great problem of Nepal. One of the reasons for rapid population growth rate is early marriage and childbearing. More than one-third of the girls are married before the age of 19 in Neapal. ${ }^{3}$ Risk of death following pregnancy is twice as great for women between 15 and 19 years than those between the ages of 20 and $24 .^{4}$

Adolescent pregnancy are at increased risk for neonatal complications as prematurity, low birth weight, IUGR, neonatal mortality and still birth. ${ }^{5-23}$ The maternal complications like PIH, preeclampsia, and anemia in pregnancy, perineal tear and episiotomy are also common among adolescents. ${ }^{8,9,11}$ However, cesarean section (CS), instrumental delivery and premature rupture of membrane, 
APH and postdated were not found significantly associated with adolescents pregnancy. 9,12-13,17,23,24However, the evidence for major impairment of pregnancy outcome among teenage mother with provision of high-quality maternal care are not found.$^{26,27}$

Though adolescents have more adverse pregnancy outcomes than adult women, it is not known if these complications are related to biological or socioeconomical factors. ${ }^{18,25}$ Similarly adolescent pregnancy was concerned more as public health issue than clinical practice. ${ }^{28}$ Other reports suggested that adolescent pregnancies have favourable obstetric outcome and are not considered as high risk pregnancies. ${ }^{26}$ This study compared the maternal and neonatal outcome of teenage mothers (1519 years) with young mothers (20-24 years) to determine if adolescent pregnancies have increased risk of adverse outcomes.

\section{METHODS}

The research design for the study was descriptive cross sectional study. This study was conducted at maternity Ward of Kathmandu University Hospital, Kavrepalanchowk district, Nepal. Non probability sampling that was purposive sampling technique was used. Total sample size was 569 . All the primiparous mothers of $15-19$ years $(n=168)$ and 20-24 year $(n=401)$ recorded in the delivery record book of Dhulikhel Hospital from June 2007 to May 2008 (1 year period) were included in the study. Record of mothers with incomplete information and with twin delivery was excluded. Approval from the obstetric department and from Dhulikhel hospital was taken. Chi-square test and relative risk (RR) for subgroups of this study population was examined using the SPSS version 10.0 .

\section{RESULTS}

a. Age of the mother and birth weight

The result showed that the adolescent mothers had to some extent higher prevalence of low birth weight $(28 \%$ versus $25.7 \%$ ) and the relative risk RR was 1.124 (0.7501.684) at $95 \%$ confidence interval of having low birth weights compared to $20-24$ years age group. Calculated value in $1 \mathrm{df}$ is 0.320 and $p$ value is 0.572 . It is not statistically significant at 0.05 confidence interval. Hence, there is no association between the age of the mother and the birth weight (Table 1).

Table 1. Association of Age of Mother with Birth Weight

\begin{tabular}{|lllll} 
Age of the mother & $<2.5 \mathrm{~kg}$ & $\geq 2.5 \mathrm{Kg}$ & Total & $p$ value \\
\hline $15-19$ years & $47(28)$ & $121(25.7)$ & 168 & 0.572 \\
$20-24$ years & $103(25.7)$ & $298(74.3)$ & 401 & \\
Total & $150(26.3)$ & $419(73.7)$ & 569 &
\end{tabular}

Note: Values in the parenthesis indicate percent. b. Age of the mother and gestational age at birth

It was found that preterm birth was less among the adolescents mothers then young mothers (7.1\% Vs. 11.5 $\%)$.The full term births were higher among adolescents as compared to young mothers $(86.9 \% \mathrm{Vs} .85 \%)$. Similarly, the post term births were common among the adolescents $6 \%$ $(n=10)$ with $3.5 \%(n=14)$ among the young mothers (Table 2).

\section{Table 2. Association of the Age of Mother with} Gestational Age at Birth

\begin{tabular}{|c|c|c|c|c|c|}
\hline $\begin{array}{l}\text { Age of the } \\
\text { mother }\end{array}$ & $\begin{array}{l}\leq 37 \\
\text { weeks }\end{array}$ & $\begin{array}{l}>37-42 \\
\text { weeks }\end{array}$ & $\begin{array}{l}>42 \\
\text { weeks }\end{array}$ & Total & $p$ value \\
\hline 15-19years & $\begin{array}{l}12 \\
(7.1)\end{array}$ & $\begin{array}{l}146 \\
(86.9)\end{array}$ & $\begin{array}{l}10 \\
(6)\end{array}$ & $\begin{array}{l}168 \\
(100)\end{array}$ & 0.141 \\
\hline 20-24years & $\begin{array}{l}46 \\
(11.5)\end{array}$ & $341(85)$ & $\begin{array}{l}14 \\
(3.5)\end{array}$ & $\begin{array}{l}401 \\
(100)\end{array}$ & \\
\hline Total & $\begin{array}{l}58 \\
(10.2)\end{array}$ & $\begin{array}{l}487 \\
(85.6)\end{array}$ & $\begin{array}{l}24 \\
(4.2)\end{array}$ & $\begin{array}{l}569 \\
(100)\end{array}$ & \\
\hline
\end{tabular}

Note: Values in the parenthesis indicate percent.

Calculated value in $1 \mathrm{df}$ is 3.925 and $p$ value is 0.141 . It is not statistically significant at 0.05 confidence interval. Hence, there is no association between the age of the mother and gestational age at birth.

\section{c. Age of the mother and neonatal complication}

This study found that the newborn of adolescents had greater neonatal complications than from the young mothers i.e. $17.2 \%$ versus $16.7 \%$ respectively. Out of total births of $569,16.9 \%$ had neonatal complication (Table 3 ).

\section{Table 3. Age of the Mother and Neonatal Complication}

\begin{tabular}{|c|c|c|c|}
\hline $\begin{array}{l}\text { Neonatal } \\
\text { complication }\end{array}$ & $\begin{array}{l}15-19 \text { years } \\
(n=168)\end{array}$ & $\begin{array}{l}20-24 \text { years } \\
(n=401)\end{array}$ & $\begin{array}{l}\text { Total } \\
(n=569)\end{array}$ \\
\hline Birth asphyxia & $1(0.6)$ & $1(0.2)$ & $2(0.4)$ \\
\hline Stillbirth & $1(0.6)$ & $3(0.7)$ & $4(0.7)$ \\
\hline Neonatal death & $1(0.6)$ & $5(1.2)$ & $6(1.1)$ \\
\hline $\begin{array}{l}\text { Intrauterine } \\
\text { death }\end{array}$ & $4(2.4)$ & $8(2)$ & $12(2.1)$ \\
\hline $\begin{array}{l}\text { Respiratory } \\
\text { distress }\end{array}$ & $1(0.6)$ & $1(0.2)$ & $2(0.4)$ \\
\hline Neonatal sepsis & $5(3)$ & $8(2)$ & $13(2.3)$ \\
\hline Jaundice & $1(0.6)$ & $1(0.2)$ & $2(0.4)$ \\
\hline Fetal distress & $5(3)$ & $23(5.7)$ & 28 (4.9) \\
\hline $\begin{array}{l}\text { Meconium } \\
\text { aspiration }\end{array}$ & $3(1.8)$ & $2(0.5)$ & $5(0.9)$ \\
\hline $\begin{array}{l}\text { Poor cry and } \\
\text { sucking }\end{array}$ & $7(4)$ & $12(3)$ & $19(3.3)$ \\
\hline Others & - & $3(0.7)$ & $3(0.5)$ \\
\hline None & 139 (82.7) & $334(83.3)$ & $473(83.1)$ \\
\hline Total & 168 (17.2) & 401 (16.7) & 569 (16.9) \\
\hline
\end{tabular}

Note: Values in the parenthesis indicate percent. 


\section{d. Age of the mother and maternal complication}

Maternal complication like APH and PPH was higher among adolescents (15-19 years). Apart from this complication, all other maternal complications are higher among young mothers (14.3\% Vs.21.7\%) (Table 4).

Table 4. Age of the Mother and Maternal Complication

\begin{tabular}{llll}
$\begin{array}{l}\text { Maternal } \\
\text { Complication }\end{array}$ & $\begin{array}{l}\text { 15-19 years } \\
(\mathbf{n}=168)\end{array}$ & $\begin{array}{l}\text { 20-24 years } \\
(\mathbf{n}=401)\end{array}$ & $\begin{array}{l}\text { Total } \\
(\mathrm{n}=569)\end{array}$ \\
\hline PIH & $2(1.2)$ & $6(1.5)$ & $8(1.4)$ \\
\hline Obstructed labor & $12(7.1)$ & $29(7.2)$ & $41(7.2)$ \\
\hline PROM & $5(3)$ & $24(6)$ & $29(5.1)$ \\
\hline APH & $4(2.4)$ & $7(1.7)$ & $11(1.9)$ \\
\hline PPH & $1(0.6)$ & $1(0.2)$ & $2(0.4)$ \\
\hline Rh negative & - & $8(2)$ & $8(1.4)$ \\
\hline Others & - & $20(5)$ & $20(3.5)$ \\
\hline None & $144(85.7)$ & $314(78.4)$ & $458(80.5)$ \\
\hline Total & $168(14.3)$ & $401(21.7)$ & $569(19.5)$ \\
\hline
\end{tabular}

Note: Values in the parenthesis indicate percent.

e. Age of the mother and mode of delivery

Normal delivery was more common among adolescent (77.4\%) as compared with young mothers (74.6\%). Cesarean section rates were more common among the young mothers $21.7 \%$ compared with $19.6 \%$ among the adolescents. Instrumental delivery with vacuum or forceps was found almost equal in both the groups.

\section{DISCUSSION}

It is well recognized that the pregnancy in adolescent is associated with an increased risk of poor maternal and fetal outcome. Teenage mothers were nearly three times more at risk of developing anemia and delivering preterm. ${ }^{30}$ They were twice as likely to develop hypertensive problems in pregnancy and were more likely to deliver vaginally with no significant increase in the risk of assisted vaginal birth or $\mathrm{C} / \mathrm{S} .{ }^{30}$ Several studies from Nepal have documented poorer outcomes for children born to adolescent mothers compared to older mothers. ${ }^{31,32}$

In this study the outcome of teenage pregnancy (15-19 yrs) to a group of young pregnant women (20-24 yrs) was compared. It revealed that $28 \%$ of low birth weight was found to the mothers of 15-19 years age group. Similar findings were present in different studies ${ }^{5,6,8-14,16-23}$ where low birth weight was the important determinants of child mortality and the outcome of adolescent pregnancy. Unlike other studies ${ }^{7,19,29}$ this study revealed no association between adolescence pregnancies and preterm birth. The rate of cesarean section was found fewer in adolescent mother. One possible explanation was the higher incidence of low birth weight infants in adolescent pregnancies, which could be associated with higher chance of vaginal delivery. Instrumental deliveries were found almost equal in both the groups in this study. APH and PPH was found higher among teenage mothers in this study, whereas it was found significantly higher in $>=20$ years age group. ${ }^{12}$ Other than APH and PPH, no other maternal complications were higher in adolescent mothers to young mothers. Among the neonatal complication, newborn of adolescents had greater neonatal complication than from the young mothers i.e. $17.2 \%$ Vs $16.7 \%$ respectively.

Though outcomes of adolescent pregnancy is adverse for both mother and fetus or newborn, there is no evidence found for major impairments of pregnancy outcomes such as preterm delivery, fetal growth restriction, LBW, fetal or perinatal death among teenage mothers, ${ }^{26}$ Similar to this study, the present study revealed fewer adverse outcome of adolescent pregnancy. Teenage pregnancy may not be an independent risk factor for adverse birth outcomes. The increased risk probably was attributable to other factors that were related to teenage pregnancy such as cultural practices, poor socioeconomic conditions, low literacy rate, inadequate prenatal, and perinatal care, and utilization of contraceptive services. ${ }^{30}$ Biological immaturity may be associated with adverse pregnancy outcomes. ${ }^{26}$ However, another study revealed that age itself is not a risk factor, and poor outcomes are linked more with socioeconomic factors rather than with biological factor. ${ }^{27}$ Other researchers have failed to find any evidence for major impairment of pregnancy outcome among teenage mother with provision of high-quality maternal care with complete coverage. ${ }^{26,27}$

The minimum adverse effects of adolescent pregnancy in this study population may at least partly be from the high quality of maternity care provided at $\mathrm{KUH}-\mathrm{DH}$ with implementation of Safe Delivery Incentive Program (SDIP) and free delivery charge.

The secondary source of data from the hospital records were utilized to collect the information, so important variables might be excluded from the study. And also findings of the study cannot be generalized.

\section{CONCLUSION}

Low birth weight was the common neonatal complication among adolescent group. Likewise, antepartum hemorrhage and postpartum hemorrhage were more common maternal complication though they were not statistically significant. Adverse outcomes of adolescent pregnancy could be attributed not only to lower maternal age but also to their relatively disadvantaged socioeconomic background, quality of prenatal visits and their family supports. Strict enforcement of laws prohibiting teenage marriage in a country like Nepal is needed to prevent from adolescent pregnancy. For those who are already pregnant at teenage, quality maternity services should be provided. In order to reduce occurrence of adolescent childbearing and its consequences, education/information may provide benefit to those female adolescents with inconsistent pregnancy intentions. 


\section{REFERENCES}

1. The WHO study group on young people and health for all by the year 2000. Young people's health-a challenge for society. Geneva: World health organization, WHO technical report series 1986 No. 731

2. Department of reproductive health and research. WHO library cataloging in publication data, WHO, Geneva 2004.

3. Ministry of health and population New era and ORC Macro. Nepal Demographic Health survey 2006. Kathmandu: ministry of health and population. 2007

4. Discussion papers on Adolescence Issues in adolescent health and development. Department of reproductive health and research. WHO library cataloging in publication data, WHO, Geneva 2004

5. Canbaz S, Sunter AT, Cetinoglu CE. Obstetric outcomes of adolescent pregnancies in Turkey. Journal in Advance therapy 2005; 22 (6): 63641.

6. Chen XK, Wen S, Fleming N, Demissie K, Rhoads GG, Walker K. Teenage pregnancy and adverse birth outcomes: A large population based retrospective cohort study. International Journal of Epidemiology 2007; 36 (2): 368-73.

7. Smith GCS, Pell JP. Teenage pregnancy and risk of adverse perinatal outcomes associated with first and second births: population based retrospective cohort study. BMJ 2001 Sept; 323: 1-5.

8. Malla K. Thesis on Adolescent pregnancy: Associated risk factors with maternal and fetal outcome at Maternity Hospital [PhD thesis]. Institute of Medicine.Maharajgunj Nursing Campus, Kathmandu. 2059 Bikram sambat.

9. Netherland S. Adverse perinatal outcomes of adolescent pregnancies in Cameroon. Maternal and Child health journal 2008; 12 (2): 14954.

10. Keskinoglu P, Nurcan B, Metin P, Hatice G, Nuriye K, Turkan A. Perinatal outcomes and risk factors of Turkish adolescent mothers. Journal of paediatric and adolescent gynaecology 2007; 20 (1): 1924.

11. Kumar A, Singh T, Basu S, Pandey S, Bhargava V. Outcome of teenage pregnancy. The Indian Journal of paediatrics 2007; 74 (10): 927-31.

12. Trivedi SS, Pasrija S. Teenage pregnancies and their Obstetric Outcomes. Adolescent Health journal 2007; 37 (2): 85-8

13. Nasreen SA, Haque MM. Pregnancy outcome in adolescent and adult-a case comparison study. Journal on adolescent health 2006; 15 (1): 15-21.

14. Puchner $\mathrm{M}$, Boutsikou T. Adolescent pregnancy and perinatal outcome. Online oxford journals 2006; 3 (1): 170-1.

15. Ramahi MA, Saleh S. Outcome of adolescent pregnancy at a university hospital in Jordan. Arch gynecol Obster 2006; 273: 207-10.

16. Mukhopadhyay P, Chaudhuri RN, Paul B. Hospital-based perinatal outcomes and complications in teenage pregnancy in India. J Health Popu, Nutr 2010 Oct; 28 (5): 494-500.

17. Briggs MM, Hopman WM, Jamieson MA.. Comparing pregnancy in adolescents and adults: Obstetric outcomes and prevalence of anemia. Journal of Obstetrics and Gynecology 2007; 29 (7): 546-55.
18. Holdre K, Rahu K. Is a poor pregnancy outcome related to young maternal age? A study of teenagers in Estonia during the period of major socioeconomic changes (from 1992-2002). European Journal of reproductive Health 2007; 131 (18): 41-5

19. Fraser AM, Brockert JE, Ward RH. Association of young maternal age with adverse reproductive outcomes. The new England Journal of Medicine. 1999; 332 (17): 1113-8

20. Mehra S, Agrawal D. Adolescent pregnancy outcomes in India. Journal of Indian Pediatrics. 2004; 41(3): 137-45.

21. Connolly G, Kennelly S.. Teenage pregnancy in Rotunda hospital Department of Obstetric and Gynaecology. Rotunda Hospital, Dublin. 2003; 12 (10): 2303-5.

22. Magadi M, Agwanda A, Obare F \& Taffa N. Size of newborn and Caesarian section deliveries among teenagers in Sub Saharan Africa: Evidence from DHS. Centre for research in social policy (CRSP) 2002; 32 (1): 36-48.

23. Medical University of Graz (Austria),. A study on teenage pregnancies between 1983-1987 and 1999-2005.Department of Obstetrics and Gynecology 2008; 34 (2): 195-8.

24. Simoes VMF, Silva AAM, Bettiol H, Lamyfilho F, Tonial SR, Mochel, EG, (2003) Characteristics of adolescent pregnany. Department of obstetrics and gynaecology. Brazil 2003; 37(5): 559-65.

25. Makinson C. The health consequences of teenage fertility. Fam Plann Perspectn 1985; 17: 132-9.

26. Raatikainen K, Heiskanen N, Verkasalo PK, Heinonen S. Good outcome of teenage pregnancies in high-quality maternity care. Eur J Public Health 2006; 16: 157-61.

27. Scanlon KS, Yip R, Schieve LA, Cogswell ME. High and low hemoglobin levels during pregnancy: differential risks for preterm bith and small for gestational age. Obstet Gynecol 2000; 96:741-8

28. Zeck W, Walcher K, Tamusino K, Lang U. Adolescent Primipara: changes in Obstetrical risk between 1983-1987 and 1999-2005. Journal of Obstetrics and Gynecology research.2008; 34 (2): 195-8.

29. Jolly MC, Sebire N, Harris J, Robinson S, Regan L. Obstetric risks of pregnancy in women less than 18 years old. Obstet Gynecol 2000; 96: 962-6.

30. Mahavarkar SH, Madhu CK, Mule VD. A comparative study of teenage pregnancy. Journal of Obstetrics and Gynecology 2008; 28 (6): 604-7

31. Sharma V, Katz J, Mullany L, Khatry S, LeClerg S, Shrestha S et al. Young maternal age and the risk of neonatal mortality in rural Nepal. Arch Pediatr Adolesc Med 2008; 162 (9): 828-35.

32. Yadav S, Choudhary D, KC N, Mandal RK, Sharma A, Chauhan SS, et al. Adverse reproductive outcomes associated with teenage pregnancy. Mcgill J Med 2008; 11(2): 141-4. 